\title{
Áreas Urbanas Funcionais (FUAs): Um estudo exploratório a partir da análise dos deslocamentos pendulares na região do Vale do Rio Pardo - RS -Brasil
}

\author{
Carolina Rezende Faccin ${ }^{1}$ \\ Leonardo Lumi da Silveira ${ }^{2}$ \\ Grazielle Betina Brandt ${ }^{3}$ \\ Rogério Leandro Lima da Silveira
}

\section{RESUMO}

Um dos métodos de análise que auxiliam na compreensão das dinâmicas entre regiões é o da delimitação de Áreas Urbanas Funcionais (FUAs), que se referem à categorização de núcleos urbanos centrais inter-relacionados a outros municípios por fluxos de pessoas, bens e serviços. Nesse sentido, este estudo exploratório, objetiva identificar possíveis FUAs na região do Vale do Rio Pardo. Para isso, foram coletados dados secundários referentes aos deslocamentos pendulares (para estudo e trabalho), utilizando-se dos microdados do Censo Demográfico de 2010 do IBGE. Pode-se observar a constituição de duas FUAs na região do Vale do Rio Pardo, sendo a de Santa Cruz do Sul e a de Venâncio Aires, evidenciando uma importante articulação econômica entre os municípios da região em relação ao mercado de trabalho e uma forte influência de Santa Cruz do Sul na dinâmica territorial e na rede urbana regional.

Palavras-chave: Áreas Urbanas Funcionais. Rede Urbana. Dinâmica Territorial. Deslocamentos pendulares. Região do Vale do Rio Pardo.

\section{ABSTRACT}

One of the methods of analysis that helps to understand the dynamics between the regions and the delimitation of Functional Urban Areas (FUAs), which refer to the categorization of central urban centers interrelated to other municipalities by flows of people, goods and services. In this sense, this objective exploratory study identifies possible FUAs in the region of Vale do Rio Pardo. For this, secondary data were collected referring to the commuting displacements, using the microdata of the IBGE Demographic Census of 2010. It is possible to observe a constitution of two FUAs in the region of the Rio Pardo Valley, being one of Santa Cruz do Sul and Venâncio Aires, evidencing an important economic articulation between the municipalities of the region in relation to the labor market and a strong influence of Santa Cruz do Sul in the territorial dynamics and regional urban network.

Keywords: Functional Urban Areas. Urban Network. Territorial dynamics. Displacements commuting. Rio Pardo Valley Region.

\footnotetext{
${ }^{1}$ Aluna do Curso de Arquitetura de Arquitetura e Urbanismo da Universidade de Santa Cruz do Sul-UNISC.

${ }^{2}$ Aluno do Curso de Relações Internacionais da Universidade de Santa Cruz do Sul.

${ }^{3}$ Professora do Programa de Pós-Graduação em Desenvolvimento Regional e do Departamento de Comunicação Social na Universidade de Santa Cruz do Sul.

${ }^{4}$ Professor do Programa de Pós-Graduação em Desenvolvimento Regional e do Departamento de História e Geografia na Universidade de Santa Cruz do Sul. < rlls@unisc.br>
} 


\section{INTRODUÇÃO}

No contexto dos estudos urbanos e do planejamento urbano e regional, a noção de policentrismo pode auxiliar no planejamento de regiões com maior coesão territorial e cidades com núcleos urbanos complementares. Conforme Silveira et al (2017), o policentrismo está relacionado a existência de um conjunto de centros urbanos, com diferentes funções econômicas e de gestão, com distintas capacidades e condições de centralidade urbana, que se relacionam funcionalmente entre si. Desse modo, métodos que diagnostiquem funcional e morfologicamente regiões, e que auxiliem na compreensão das dinâmicas inter e intra regionais, se tornam essenciais.

Assim, um dos métodos de análise disponíveis, que utilizam o policentrismo como recurso, é o da delimitação das áreas urbanas funcionais (Funcional Urban Áreas - FUAs). Além disso, segundo Antikainen (2005), a delimitação de FUAs torna possível a análise de interações entre cidades em diferentes escalas. Por sua vez, de acordo com o ESPON (2004), em suma, uma FUA é uma área urbana ligada à municípios adjacentes através do deslocamento de pessoas, bens, serviços, informações e entre outros.

Tendo em vista esse pressuposto, utilizaremos o conceito de policentrismo para compreender a dinâmica territorial na escala regional. Mais exatamente interessa-nos abordar o potencial metodológico e analítico do conceito de FUAs para os estudos urbanos e regionais, notadamente em relação ao seu uso para a análise e interpretação do desenvolvimento da dinâmica territorial, em contextos regionais (SILVEIRA et al, 2017).

Para isso, nesse estudo exploratório, que utiliza como recorte espacial a região do Vale do Rio Pardo, objetiva-se identificar a existência de possível FUAs nessa região, através da análise de dados sobre os deslocamentos pendulares, levantadas pelo IBGE no Censo Demográfico de 2010. Essa pesquisa dá continuidade as ações de pesquisa e extensão do Observatório de Desenvolvimento Regional (OBSERVA-DR), que se constrói a partir de uma rede interinstitucional de reflexão, pesquisa e contribuição teórico-metodológica sobre o tema do desenvolvimento regional. Além disso, esse trabalho é vinculado ao Programa de PósGraduação em Desenvolvimento Regional da Universidade de Santa Cruz do Sul (UNISC) e ao Grupo de Pesquisa e Estudos Urbanos e Regionais. ${ }^{5}$

\footnotetext{
${ }^{5}$ As reflexões deste artigo remetem à estudos realizados por bolsistas de iniciação científica, em fase inicial e exploratória do trabalho de identificação das FUAs, procurando se apropriar da metodologia e dos conceitos apresentados. Os resultados completos da análise foram publicados no artigo Policentrismo, Áreas Urbanas Funcionais (FUAs) e Dinâmica Territorial: Um estudo exploratório desde a região do Vale do Rio Pardo-RSBrasil, publicado pela Revista Redes, nº 22, em 2017.
} 


\section{FUNDAMENTAÇÃO TEÓRICA}

\subsection{Policentrismo}

Apesar da noção de policentrismo ter surgido em meados dos anos 1930, no âmbito da Escola de Chicago e na conceituação de espaços urbanos, seu uso na escala interurbana é recente. Além disso, embora seu conceito não tenha clara definição, ele vem sendo muito usado pelo Observatório Europeu de Ordenamento do Território (ESPON), no contexto do desenvolvimento territorial europeu, objetivando maior integração e coesão territorial. (DAVOUDI, 2003)

Adotado pelo ESPON, o policentrismo funcional europeu, tem dois aspectos complementares. A primeira refere-se à morfologia, isto é, à distribuição das áreas urbanas em um dado território (número de cidades, hierarquia, distribuição). O segundo diz respeito às relações entre as zonas urbanas, ou seja, as redes de fluxos e de cooperação. Estes fluxos estão geralmente relacionados com a proximidade, embora as redes também possam ser independentes da distância. Ou seja, um sistema urbano policêntrico requer que os pressupostos morfológicos estejam associados à capacidade das cidades se relacionarem funcionalmente entre si. (ESPON, 2004)

A noção de policentrismo opõe-se ao monocentrismo, no qual a competência de prestação de serviços e de gestão territorial está cada vez mais concentrada num único centro. Em vez disso, a policentricidade promove os tipos equilibrados e multiescalares de redes urbanas, mais benéficas do ponto de vista social e econômico, tanto para as áreas centrais como para as periferias. (ESPON, 2004) A região metropolitana de Rhine-Ruhr, na Alemanha, é um exemplo de rede urbana policêntrica, em contraste com a região de BerlinBrandeburgo, em que Berlim é claramente dominante (DAVOUDI, 2007) (Figura 1).

O policentrismo também está diretamente ligado à noção de rede urbana que, conforme Correa (2006) é "o conjunto funcionalmente articulado de centros, que se constitui na estrutura territorial onde se verifica a criação, apropriação e circulação do valor excedente." Logo, quanto maior a policentricidade da região, melhor articulada estará sua rede urbana.

Assim, no contexto dos estudos regionais, o conceito de policentrismo adquire importância por possibilitar melhor entender a topologia, a configuração espacial, e o conteúdo desses diferentes e complexos fluxos que atravessam o território. Com isso, percebe-se o seu potencial para compreensão da dinâmica territorial e da rede urbana, bem como para análise e delimitação das FUAs, principalmente em escalas regionais. (SILVEIRA et al, 2017). 
Figura 1 - Região urbana monocêntrica versus policêntrica

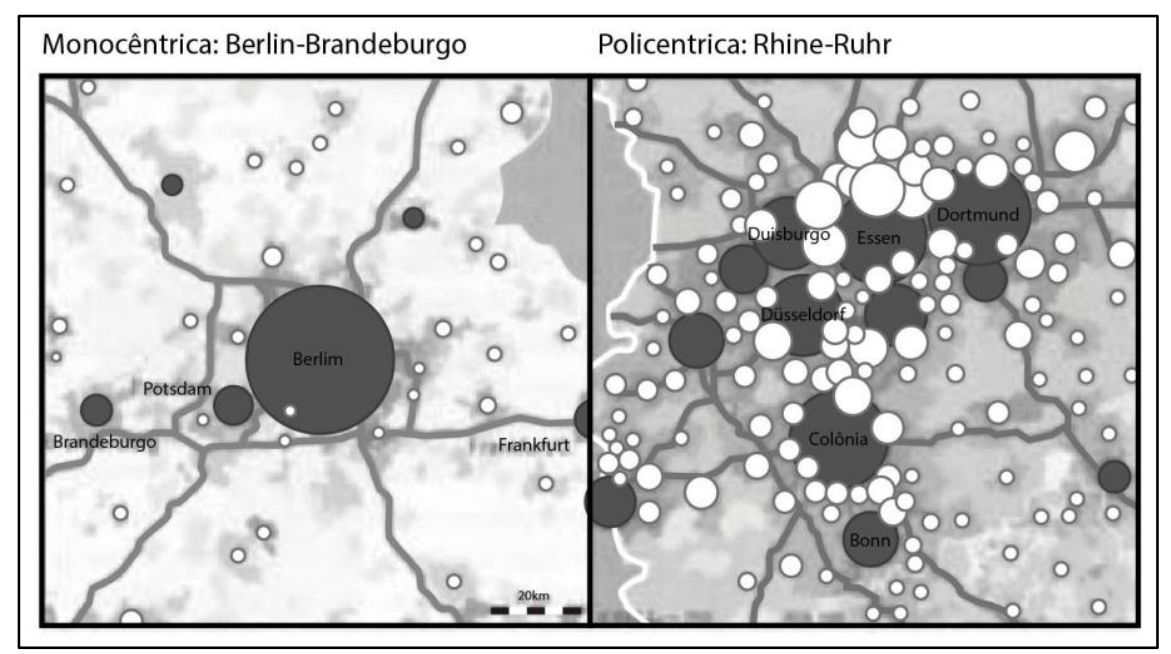

Fonte: Carolina Faccin, a partir de Davoudi (2007)

\section{2 Áreas Urbanas Funcionais}

A FUA é um tipo de região funcional. Como tal, é caracterizada por ser uma unidade territorial espacialmente integrada pelas atividades socioeconômicas da população, como fluxos de comércio de bens e serviços, deslocamentos para trabalho e compras domésticas. (KARLSSON; OLSSON, 2006; SÝKORA; MULÍČEK, 2009). Além disso, é constituída por núcleos urbanos centrais contíguos de áreas urbanas morfológicas ou morfological urban areas (MUAs), com municípios no seu entorno, a partir dos quais há um percentual mínimo da população que se desloca para o trabalho, para as MUAs. (ESPON, 2004). Ou seja, a FUA possui dois tipos de estruturas: a morfológica e a relacional.

Do ponto de vista morfológico, as MUAs correspondem a espaços urbanos que possuem pelo menos, $650 \mathrm{hab} / \mathrm{Km}^{2}$. Estas por sua vez, são as bacias de emprego definidas pelos movimentos pendulares casa-trabalho que tem origem nos espaços localizados em torno das MUAs. Ela ainda pode ser mononuclear, quando uma cidade principal apresenta a principal centralidade na região funcional, ou polinuclear, quando essa centralidade é compartilhada por mais de uma cidade principal no interior da região funcional. (ESPON, 2011)

Do ponto de vista relacional, as FUAs correspondem a uma área urbana de pelo menos 15 mil habitantes e uma população total de no mínimo 50 mil habitantes. Ela inclui uma ou mais MUAs e as respetivas áreas circundantes, em que pelo menos $10 \%$ da população trabalha na MUA. Sua estrutura relacional pode ser mono ou multidirecional, quanto às 
direções que os fluxos entre as cidades assumem no interior da região funcional. (Figura 2) (ESPON, 2011)

Nesse sentido, a metodologia para identificação de FUAs torna-se importante, pois possibilita a análise da dimensão territorial da divisão do trabalho e dos processos de interação socioespacial, assim como identifica as inter-relações e os diferentes níveis de centralidade entre as cidades de uma dada região e suas áreas de influência no território regional (SILVEIRA et al, 2017). Além disso, tem capacidade de ultrapassar fronteiras administrativas, já que, na maioria dos casos, as estatísticas baseadas em limites morfológicos ou políticos não refletem o papel real desempenhado por uma cidade. (ANTIKAINEN, 2005)

Figura 2 - Tipos de estruturas morfológicas e relacionais em FUAs

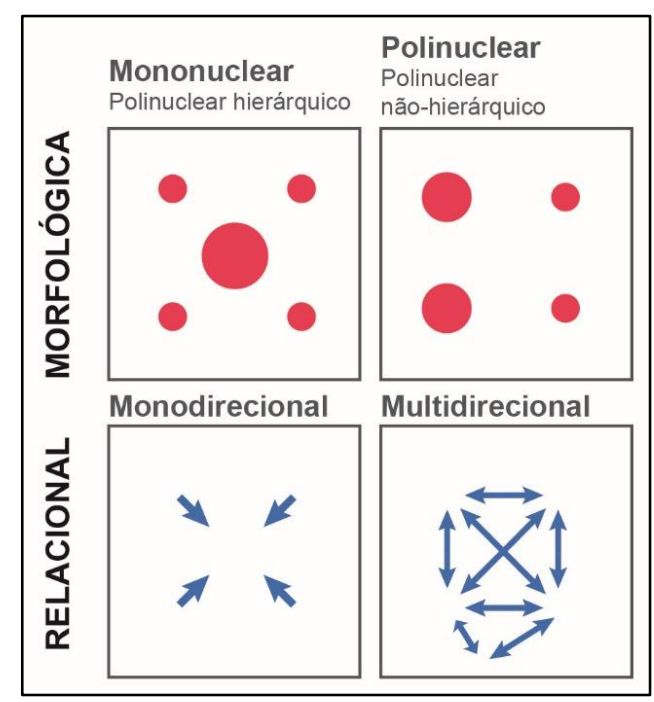

Fonte: Carolina Faccin, a partir de ESPON (2004).

\section{METODOLOGIA}

A construção do estudo exploratório sobre uma possível existência de FUAs, na região do Vale do Rio Pardo, consistiu inicialmente de uma revisão bibliográfica sobre os conceitos de rede urbana, policentrismo e das FUAs e suas aplicações em países da União Europeia. Após esse processo, uma ampla base de dados foi construída sobre deslocamentos pendulares, tendo como base a População Economicamente Ativa que se deslocava para trabalho e estudo entre as cidades do Vale do Rio Pardo, identificando os locais de origem e de destino e a quantidade de pessoas que compõe esses fluxos. Essa etapa envolveu 
metodologicamente a utilização dos $\operatorname{microdados}^{6}$ relativos aos deslocamentos pendulares para trabalho e estudo do Censo Demográfico de 2010. Vale ressaltar que, devido à grande quantidade de informação presente nos microdados, ao invés da utilização de softwares estatísticos tradicionais optou-se pela utilização de um sistema de banco de dados relacional, que maneja com mais eficiência grandes massas de dados e possibilita o cruzamento de dados através da linguagem SQL (Structured Query Language).

Em seguida, os dados foram confrontados com as algumas variáveis, como a densidade demográfica e o commuting (deslocamento), estabelecidas pelo ESPON e OCDE, para a União Europeia. No entanto, sabemos que estas variáveis foram estabelecidas conforme a estrutura espacial e as dinâmicas econômicas, demográficas e urbanas das regiões europeias. Em paralelo, Sýkora e Mulíček (2009) estabeleceram algumas críticas a estas duas organizações por aplicarem critérios uniformes de dimensão em toda a Europa, sem levar em conta as diferenças qualitativas entre os países. Os autores observaram ainda que caso a análise não reflita a natureza da organização e do sistema regional, deficiências e inadequações na formulação e na tomada de decisões políticas podem ser geradas.

Nesse sentido, nos estudos desenvolvidos na Espanha por Pillet Capdepón et al (2007) e Pillet et al (2010), bem como aqueles desenvolvidos na República Theca por Sýkora e Mulíček (2009), e em Portugal por Ferrão (2012), revelam a possibilidade do uso e aplicação do conceito de FUA adaptando os parâmetros gerais definidos pelo ESPON e pela OCDE. Dessa forma, esses estudos buscaram, alinhar a metodologia das FUAs à realidade territorial e à dinâmica urbana e regional existente em cada país.

Por esse motivo, as variáveis foram adaptadas para realização desse estudo, de modo a utilizar parâmetros correspondentes a realidade da região do Vale do Rio Pardo. Assim, utilizamos como ponto de corte o número de deslocamentos para trabalho e estudo que obtivesse o mínimo de $10 \%$ da População Economicamente Ativa (PEA) do município de origem e que se destinassem para cidades de pelo menos 15 mil habitantes. ${ }^{7}$

Por fim, buscou-se sistematizar e organizar os microdados disponíveis, interpretando-os a partir da configuração de tabelas e mapas temáticos. Também foram analisadas algumas das características da população que se desloca para trabalho ou estudo em

\footnotetext{
${ }^{6}$ Menor nível de desagregação dos dados de uma pesquisa, retratando sob a forma de códigos numéricos o conteúdo dos questionários, preservado o sigilo estatístico com vistas à não individualização das informações.

${ }^{7}$ Observando os dados do Censo Demográfico do IBGE de 2010, verificamos que apenas cinco cidades da região se enquadram nesse porte: Santa Cruz do Sul (105.190 hab.), Venâncio Aires (41.400 hab.), Rio Pardo (25.614 hab.), Encruzilhada do Sul (17.119 hab.) e Candelária (15.715 hab.).
} 
direção ao núcleo central da FUA, como a situação de domicílio de origem, gênero e renda familiar, sendo essas características apresentadas em gráficos.

\section{RESULTADOS}

A região do Vale do Rio Pardo, localizada na zona centro-oriental do território do Estado do Rio Grande do Sul, no sul do Brasil, é atualmente, composta por 23 municípios, ocupando uma área territorial de 13.260,47 $\mathrm{Km}^{2}$. Essa região apresentava em 2010, uma população total de 418.109 habitantes $^{8}$ e densidade demográfica de 31,5 hab $/ \mathrm{km}^{2}$. (IBGE, 2010).

Devido a um conjunto de características e contingências, possui certa particularidade no âmbito nacional e internacional. Conforme Silveira e Campos (2012), desde 1970, a região é mundialmente reconhecida como uma das principais áreas produtoras e beneficiadoras agroindustriais de fumo. Nela, ressalta-se a importância das cidades de Santa Cruz do Sul, Vera Cruz e Venâncio Aires, por desempenharem um papel destacado na configuração espacial do setor fumageiro. Também é possível visualizar a expressiva importância de Santa Cruz do Sul e Venâncio Aires, tendo como base os resultados obtidos e apresentados a seguir.

Na Tabela 1 é apresentada a relação entre o número de pessoas que se desloca para trabalho e estudo com a PEA entre os municípios do Vale do Rio Pardo, com destaque para os fluxos de valor superior a $10 \%$. A tabela apresenta dados que evidenciam que em todos os municípios da região há fluxos de deslocamento, tanto como origem quanto destino. No entanto, algumas cidades se destacam por apresentarem mais fluxos de deslocamento em relação às demais. As cidades de onde mais se originam deslocamentos são Santa Cruz do Sul (14 fluxos), Sobradinho (10 fluxos), Venâncio Aires (10 fluxos) e Rio Pardo (9 fluxos). E as cidades que mais recebem deslocamentos são Santa Cruz do Sul (22 fluxos), Venâncio Aires (11 fluxos), Sobradinho (11 fluxos), Candelária (10 fluxos) e Rio Pardo (09 fluxos).

Essa desigualdade de fluxos pode ocorrer em função da localização espacial, uma vez que as atividades diárias da população, incluindo estudo e trabalho, tendem a ser realizadas perto de sua residência. Além disso, para cada centro de atividades econômicas, existe uma periferia dominada por interações com o centro. (KARLSSON; OLSSON, 2006). Ou seja, a desigualdade de fluxos também pode ocorrer em razão das diversificadas economias urbanas e estruturas de serviço presentes no território.

\footnotetext{
${ }^{8}$ Segundo o IBGE (2015), a população total da região foi estimada em 440.227 habitantes, com uma respectiva densidade demográfica de $33,2 \mathrm{hab} / \mathrm{km}^{2}$.
} 
Tabela 1 - Percentual da População Economicamente Ativa que se desloca para trabalho e estudo no Vale do Rio Pardo - 2010 Vale do Rio Pardo: Municípios de destino

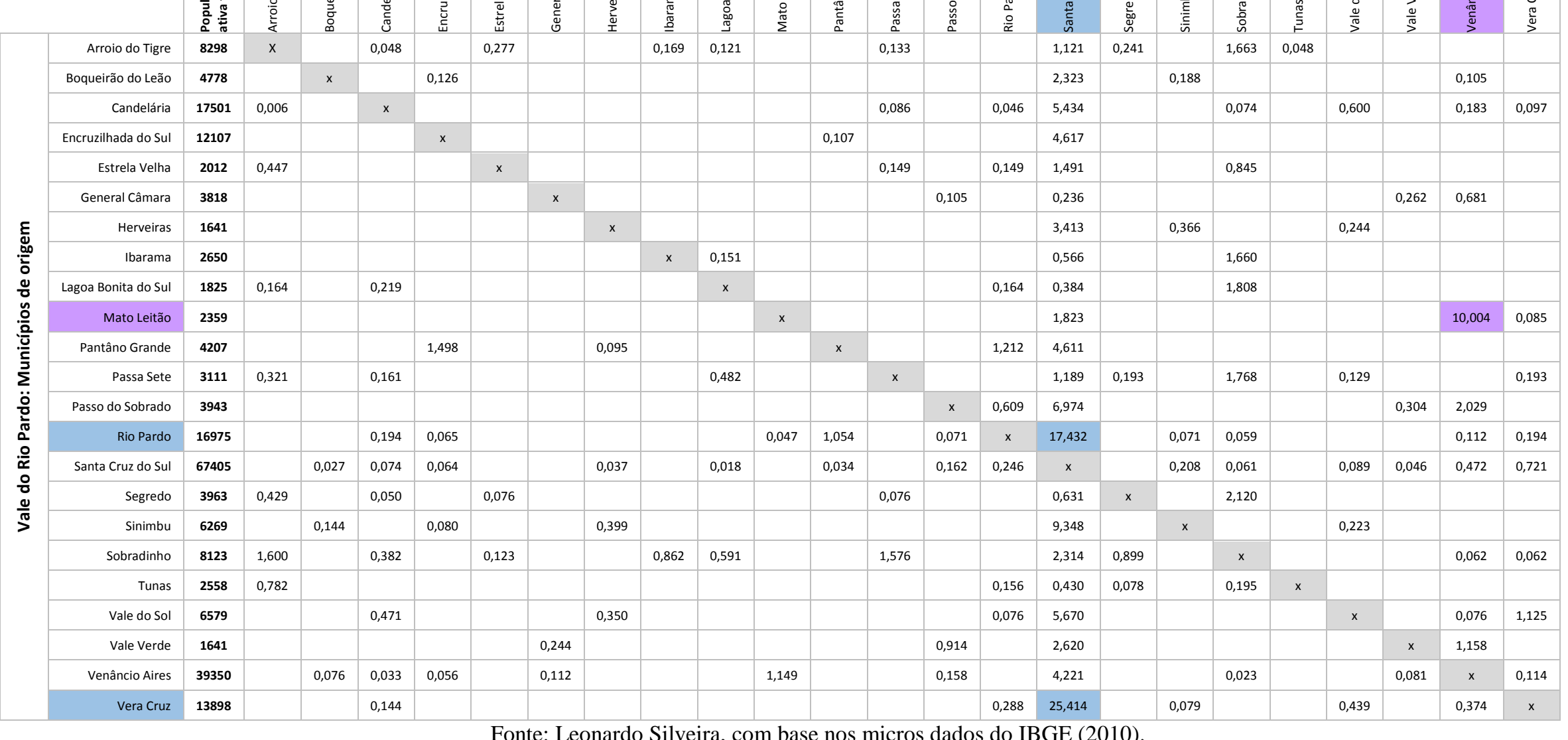


Na Figura 3 apresentamos um mapa da região, sendo este estruturado a partir dos dados informados na Tabela 1, com a representação dos movimentos pendulares para trabalho e estudo, com destino para as cidades de Santa Cruz do Sul e Venâncio Aires. As duas são justamente as cidades que atraem os principais fluxos pendulares no interior do espaço regional do Vale do Rio Pardo. Além disso, estão em destaque os fluxos identificados com percentual acima de $10 \%$.

\section{Figura 3 - Fluxos pendulares para trabalho e estudo com destino para Santa Cruz}

\section{do Sul e Venâncio Aires - 2010}

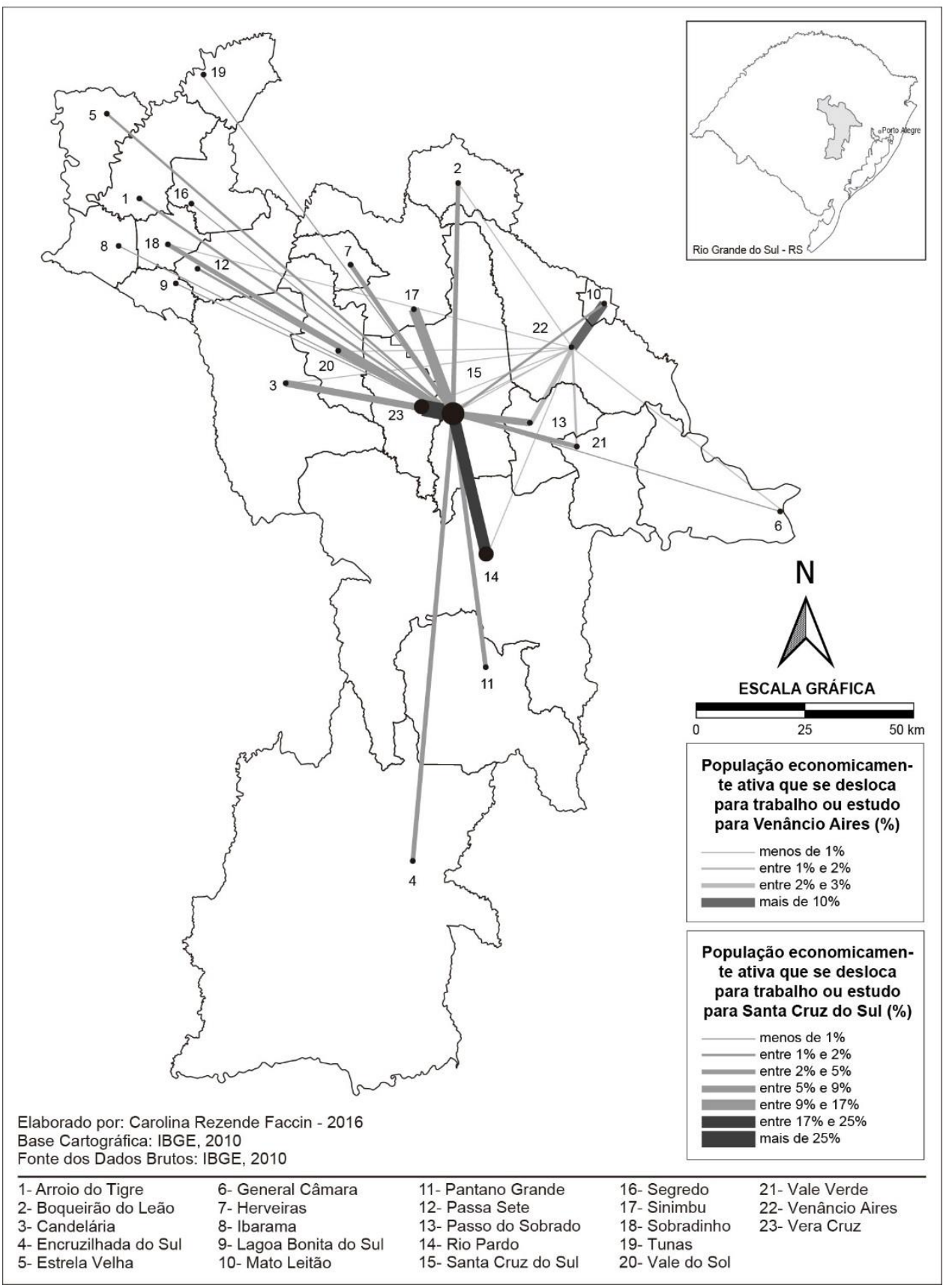

Fonte: Carolina Faccin, com base nos microdados do IBGE (2010). 
Ao observar a Tabela 1 e a Figura 3 é possível identificar os principais fluxos pendulares para trabalho e estudo com destino para Santa Cruz do Sul, sendo estes originados de Vera Cruz (25,41\% do total da população residente, representando 3.532 pessoas, sendo identificadas 2.723 pessoas para trabalho e 809 para estudo) e Rio Pardo $(17,43 \%$, do total da população residente, representando 2.959 pessoas, sendo identificadas 2.118 pessoas para trabalho e 771 para estudo). Por sua vez, o fluxo pendular originado em Mato Leitão com destino para Venâncio Aires representa $10 \%$ da população residente e, em valores absolutos, representa 236 pessoas (sendo 213 pessoas para trabalho e 23 para estudo).

A partir dos dados compilados, apresentados na Tabela 1 e na Figura 3 e do uso da metodologia das FUAs, identificaram-se duas possíveis configurações de FUAs na região do Vale do Rio Pardo: A FUA de Santa Cruz do Sul, com núcleo central em Santa Cruz do Sul, composta também pelas áreas urbanas e rurais de Vera Cruz e Rio Pardo e a FUA de Venâncio Aires, com núcleo central em Venâncio Aires, composta também pela área urbana e rural de Mato Leitão. Na Figura 3 estão representadas as configurações espaciais dessas duas FUAs, bem como as áreas com maior densidade populacional (hab/ $\mathrm{km}^{2}$ ), através de pixels de $1 \mathrm{~km}^{2}$ obtidos pela Grade Estatística de 2010 do IBGE. Além disso, está representada na tabela a rede viária intermunicipal, podendo observar sua importância nas relações funcionais e interações espaciais presentes entre os municípios das FUAs.

As duas FUAs se caracterizam por uma estrutura morfológica polinuclear hierárquica. Quanto às suas estruturas relacionais, ambas são preponderantemente monodirecionais, já que os fluxos pendulares com percentual acima de $10 \%$ são aqueles que se destinam para Santa Cruz do Sul e Venâncio Aires. Nesse contexto, Santa Cruz do Sul, cidade média com papel de comando na rede urbana regional e principal núcleo urbano regional, se destaca ao apresentar maior centralidade de sua economia urbana. Por outro lado, Venâncio Aires se apresenta como um centro de zona e as demais cidades são centros locais (Mato Leitão, Rio Pardo e Vera Cruz). Através destes dados, é evidente a importância de Santa Cruz do Sul, também como principal núcleo urbano regional e centralidade de sua economia urbana (Figura 4).

Vera Cruz se configura como o município com principal fluxo de deslocamento para Santa Cruz do Sul. O aumento dos fluxos pendulares entre as duas cidades está relacionado à proximidade espacial (aproximadamente $8 \mathrm{~km}$, percorridos em transporte rodoviário, por aproximadamente 15 minutos, pela rodovia RS-409) e a 
expansão das malhas urbanas desses municípios, até sua quase justaposição. Por sua vez, Rio Pardo é o segundo principal fluxo de deslocamento para Santa Cruz do Sul. Essa articulação entre as duas cidades é proveniente da relativa proximidade espacial (aproximadamente $31 \mathrm{~km}$ ) e um tempo estimado de deslocamento de 35 minutos, através do transporte rodoviário pela BR-471 que liga ambas as cidades.

\section{Figura 4 - Áreas Urbanas Funcionais de Santa Cruz do Sul e de Venâncio Aires}

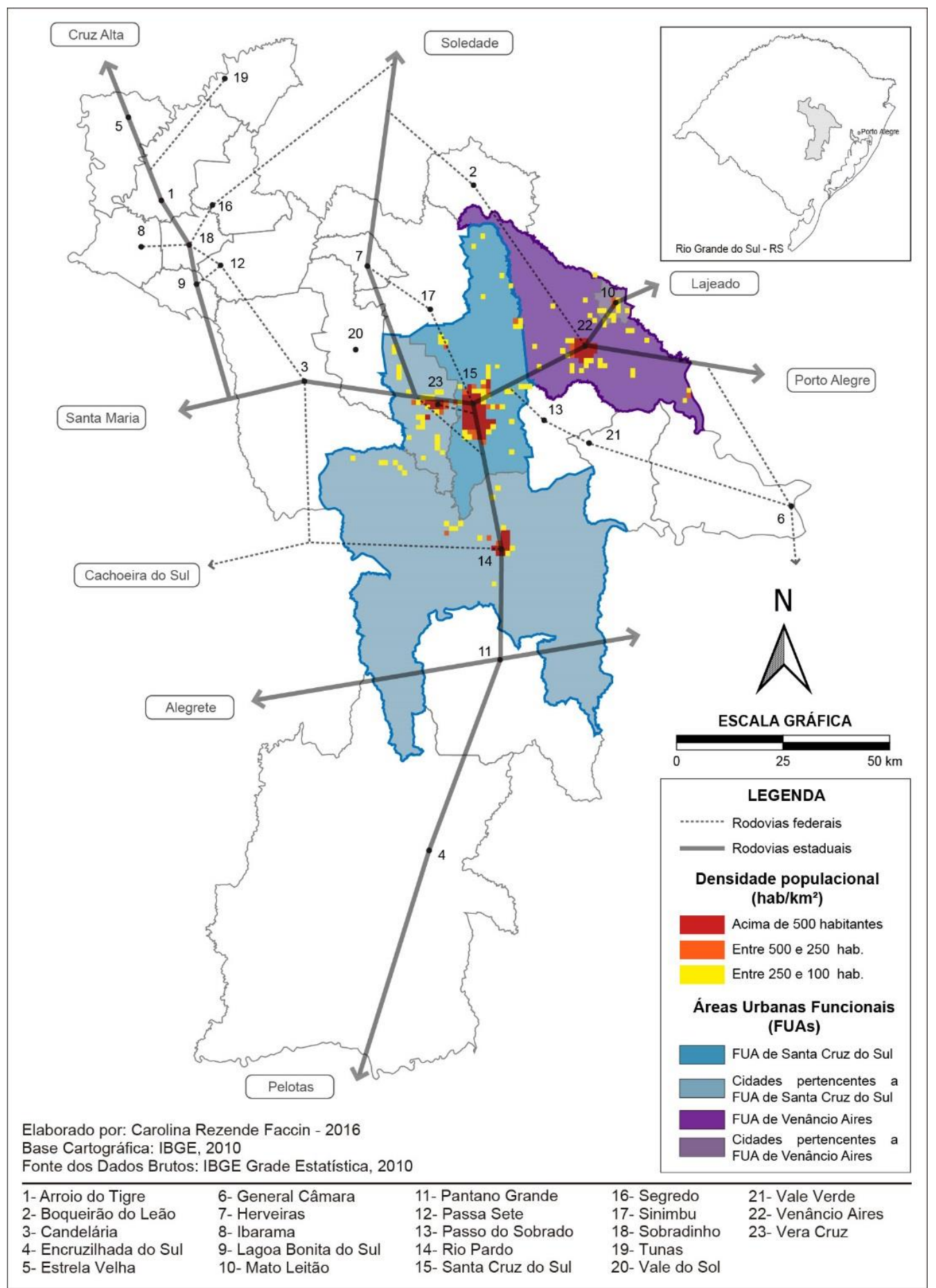

Fonte: Carolina Faccin com base nos microdados do IBGE (2010). 
Em relação à FUA de Venâncio Aires, há somente um fluxo de deslocamento de relevância: o de origem em Mato Leitão com destino à Venâncio Aires. O pequeno município de Mato Leitão possuía em 2010 uma população urbana de 1.621 habitantes, com 58\% da população total residente no meio rural (IBGE, 2010). Conforme Silveira et al (2017), a relação entre os dois municípios tem raízes históricas, na medida em que o município de Mato Leitão até 1991, integrava o território de Venâncio Aires, se emancipando politicamente deste, após aquela data. Isso evidencia que os vínculos econômicos e sociais entre os dois municípios permaneceram.

A partir do detalhamento dos microdados do IBGE (2010), referentes aos movimentos pendulares para trabalho e estudo que ocorrem nas possíveis FUAs do Vale do Rio Pardo, podemos compreender algumas das características destes fluxos e assim apreender aspectos qualitativos existentes nessa parte da região. Para isso, foram analisadas as variáveis relativas ao domicílio de origem, gênero e renda familiar.

Quanto à situação de domicílio, observa-se no Gráfico 1 que o maior contingente de pessoas que se deslocam para trabalho e estudo em ambas e possíveis FUAs tem como origem a zona urbana. O fluxo Rio Pardo-Santa Cruz do Sul apresenta $84,6 \%$ de moradores da zona urbana, Vera Cruz-Santa Cruz do Sul 71,5\% e Mato Leitão-Venâncio Aires 59,3\%. Nessa perspectiva os dados demonstram a importante integração funcional urbana entre essas cidades, ao mesmo tempo que revelam a insuficiência da oferta de empregos urbanos nas cidades de origem desses fluxos. (SILVEIRA et al, 2017)

\section{Gráfico 1 - Distribuição da população que se desloca para Santa Cruz do Sul e Venâncio Aires por origem do domicílio (2010)}

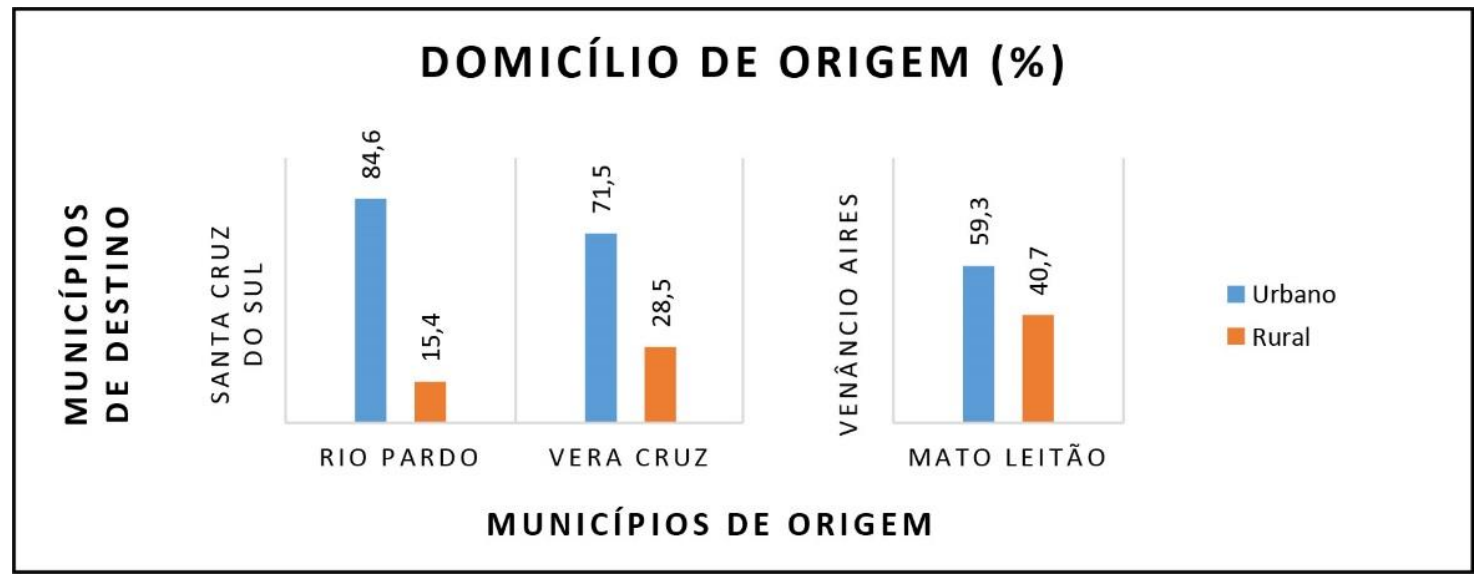

Fonte: Carolina Faccin, com base nos dados do IBGE, 2010. 
Com relação a variável gênero, nota-se através do Gráfico 2, que a maioria dos indivíduos que se deslocam são do sexo masculino, mesmo que com pouca prevalência. O fluxo Rio Pardo-Santa Cruz do Sul apresenta 57\% de homens, já Vera Cruz-Santa Cruz do Sul 51,9\% e Mato Leitão-Venâncio Aires, 59,7\%.

\section{Gráfico 2 - Distribuição da população que se desloca para Santa Cruz do Sul e Venâncio Aires por gênero (2010)}

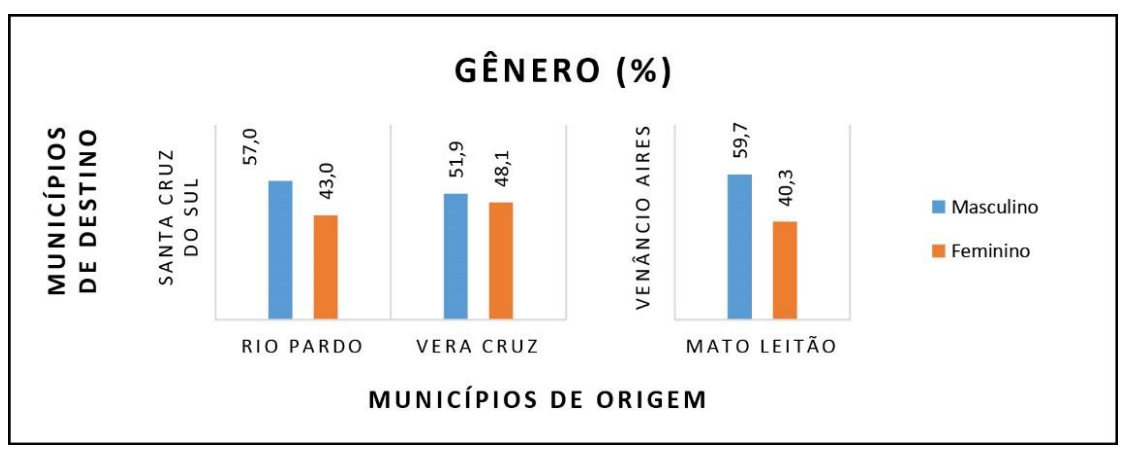

Fonte: Carolina Faccin, com base nos dados do IBGE, 2010.

Pode-se observar no Gráfico 3 que, com relação à renda ${ }^{9}$, os fluxos que mais se destacam são aqueles dos indivíduos que se enquadram na classe $\mathrm{D}$ de renda familiar mensal. O fluxo Rio Pardo-Santa Cruz do Sul apresenta 60,5\% de indivíduos da classe D, sendo que Vera Cruz-Santa Cruz do Sul apresenta 55,1\% e Mato Leitão-Venâncio Aires está representado por $63,1 \%$.

\section{Gráfico 3 - Distribuição da população que se desloca para Santa Cruz do Sul e Venâncio Aires por faixa de renda familiar (2010)}

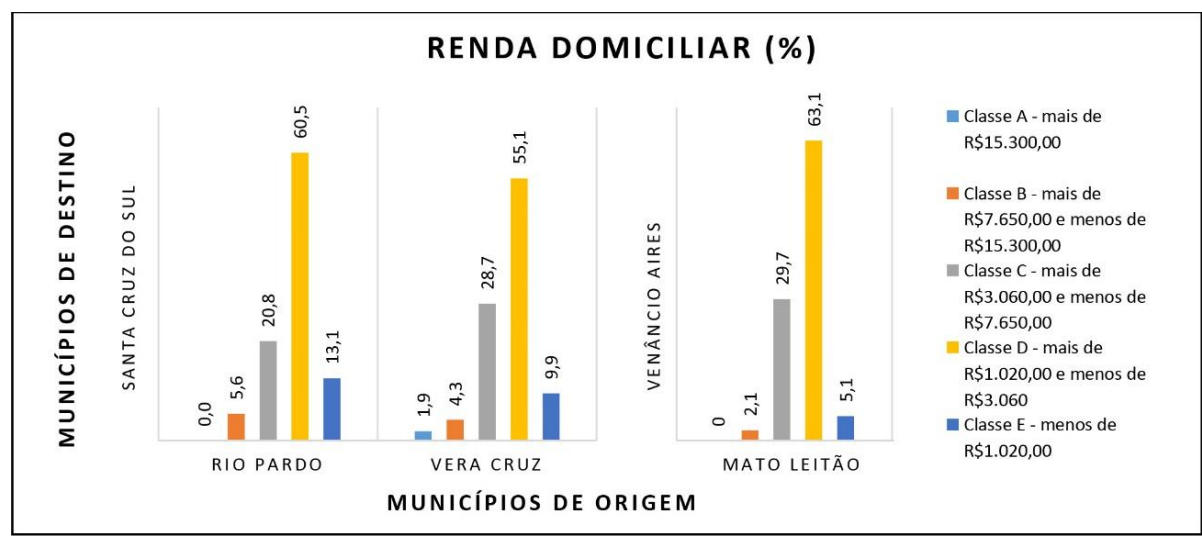

Fonte: Carolina Faccin, com base nos dados do IBGE, 2010.

\footnotetext{
${ }^{9}$ A classificação do IBGE (2010) para as classes de renda tem como base o salário mínimo nacional de 2010, de $\mathrm{R} \$ 510,00$.
} 


\section{CONCLUSÃO}

Esse estudo exploratório, que buscou aplicar a metodologia das Áreas Urbanas Funcionais (FUAs) para a região do Vale do Rio Pardo, tornou possível a observação de uma importante relação entre as cidades e revela a presença, mesmo que incipiente, de um processo de policentrismo no território. Além disso, foi possível evidenciar o papel que Santa Cruz do Sul assume como centro regional. A cidade atrai um expressivo número de fluxos de deslocamento pendular para trabalho e estudo, de todas as cidades do Vale do Rio Pardo, reforçando a centralidade da cidade na rede urbana regional.

Fica claro a importância da metodologia das FUAs e do conceito de policentrismo no auxílio para maior compreensão das dinâmicas territoriais e socioespaciais e do funcionamento da rede urbana. Além disso, o método pode auxiliar a pensar estratégias e políticas governamentais de desenvolvimento à nível regional, lançando programas que integrem e dinamizem as cidades, sem necessariamente fazer uso das delimitações político administrativas tradicionais. Também, ressalta-se a importância dessa metodologia por oportunizar uma melhor compreensão da singularidade das redes urbanas.

Embora a identificação das duas possíveis FUAs no Vale do Rio Pardo, baseada somente na análise dos fluxos pendulares, apresente muitos resultados valiosos, eles ainda são insuficientes para compreender em profundidade a região. No entanto, este estudo exploratório abre campo para o avanço da pesquisa para compilação de outros dados acerca de fluxos de capital, de mercadorias, insumos e informações, que circulam no interior da região. Desse modo, será possível realizar uma análise completa das FUAs no Vale do Rio Pardo, a fim de fornecer instrumentos para o poder público, visando novas e melhores estratégias para o desenvolvimento regional.

\section{REFERÊNCIAS}

ANTIKAINEN, J. The concept of Functional Urban Are: Findings of the ESPON Project 1.1.1. Informationen zur Raumentwicklung. Heft, 7, p.447-452, 2005. Disponível em: <http://www.bbsr.bund.de/BBSR/EN/Publications/IzR/2005/DL_Heft07_Antikainen.pd f?_blob=publicationFile\&v=3>. Acesso em: 11 abr. 2017.

CORREA, R. Estudos sobre a rede urbana. Rio de Janeiro: Ed. Bertrand Brasil. 2006. 
ESPON. The Functional Urban Areas Database - ESPON 2013 Database. 2011. Disponível em: <http://database.espon.eu/db2/jsf/DicoSpatialUnits/DicoSpatialUnits_onehtml/index.ht ml>. Acesso em: 11 abr. 2017.

ESPON. ESPON 111.Potentials for polycentric development in Europe. Project report. August, 2004. Disponível em: <https://www.espon. eu/export/sites/default/Documents/Projects/ESPON2006Projects/ThematicProjects/Poly centricity/fr-1.1.1_revised-full.pdf>. Acesso em: 11 abr. 2017.

FERRÃO, J. (Coord.) Regiões Funcionais, Relações urbano-rurais e Política de Coesão Pós-2013. Lisboa: ICS. Relatório Final. Julho, 2012. Disponível em: <http://www.qren.pt/np4/np4/?newsId=1334\&fileName=regioes_funcionais.pdf >.

Acesso em: 11 abr. 2017.

DAVOUDI, S. Polycentricity: Panacea or pipedream? In: CATTAN, N. (Org.) Cities and networks in Europe. Montrouge, France: John Libbey Eurotext, p.65-73, 2007.

Polycentricity in European Spatial Planning: From an Analytical Tool to a Normative Agenda. European Planning Studies, v.11, n.8, December, p.979-999, 2003.

IBGE. Censo Demográfico do Brasil. Rio Grande do Sul. 2010. Disponível em: <http://www.ibge.gov.br/home/estatistica/populacao/censo2010/>. Acesso em: $11 \mathrm{abr}$. 2017.

IBGE. Estimativas populacionais para os municípios e para as Unidades da Federação brasileiros. 12 ago. 12015.2 Disponível <http://www.ibge.gov.br/home/estatistica/populacao/estimativa2015/default.shtm>. Acesso em 9 mai. 2017.

KARLSSON, C., OLSSON M. The identification of functional regions: theory, methods, and applications. The Annals of Regional Science. Porto, v. 40, n. 1, p. 1-18, 2006.

PILLET, C. F. et al. Fuentes para la aplicación de la Estrategia Territorial Europea en Castilla-La Mancha. Estudios Geográficos. Madrid, v. 68, n. 263, p. 627-651, jul./dez. 2007.

Disponível

em: <http://estudiosgeograficos.revistas.csic.es/index.php/estudiosgeograficos/article/view/7 1/68>. Acesso em: 11 abr. 2017.

PILLET, F. et al. El policentrismo em Castilla-La Mancha y su análisis a partir de la población vinculada y el crecimiento demográfico. Scripta Nova. Revista Electrónica de Geografía y Ciencias Sociales. Barcelona: Universidad de Barcelona, 20 abr. 2010, v. XIV, n. 321. Disponível em: 〈http://www.ub.es/geocrit/sn/sn-321.htm>. Acesso em: 11 abr. 2017.

SÝKORA, L.; MULÍČEK, O. The micro-regional nature of functional urban areas (FUAs): lessons from the analysis of the Czech urban and regional system. Urban Research \& Practice, v. 2, n. 3, p. 287-307, 2009. Acesso em 11 abr. 2017. DOI: http://dx.doi.org/10.1080/17535060903319228 
SILVEIRA, R. L. L. da; CAMPOS, H. Á. Processos participativos em experiências recentes de planejamento regional: o caso do Vale do Rio Pardo (RS). Revista Redes. Santa Cruz do Sul, vol. 17, n. 1, p. 206-213, jan./abr. 2012. Acesso em: 11 abr. 2017. DOI: http://dx.doi.org/10.17058/redes.v17i1.2687

SILVEIRA, R. L. L. da. et al. Policentrismo, Áreas Urbanas Funcionais (FUAs) e Dinâmica Territorial: Um estudo exploratório desde a região do Vale do Rio Pardo - RS - Brasil. Revista Redes. Santa Cruz do Sul, v. 22, n. 1, p. 184-217, 2017. Acesso em: 11 abr. 2017. DOI: http://dx.doi.org/10.17058/redes.v22i1.8641

Como citar este documento: FACCIN, Carolina Rezende et al. Áreas Urbanas Funcionais (FUAs): Um estudo exploratório a partir da análise dos deslocamentos pendulares na região do Vale do Rio Pardo - RS -Brasil. Revista Jovens Pesquisadores, Santa Cruz do Sul, v. 7, n. 1, jan. 2017. ISSN 2237-048X. Disponível em: <https://online.unisc.br/seer/index.php/jovenspesquisadores/article/view/9319>. Acesso em: ... doi: http://dx.doi.org/10.17058/rjp.v7i1.9319. 